\title{
Clinical Profile and Outcome of Acute Kidney Injury in Elderly Adults in a Tertiary Hospital in Cameroon
}

\section{Fouda Menye Epse Ebana Hermine Danielle1,2*, Ladze Clavis Berinyuy', Mahamat Maimouna ${ }^{1,3}$, Nzana Victorine Bandolo ${ }^{1,4}$, Ndjong Emmanuel ${ }^{4}$, Kaze Folefack Francois ${ }^{1,4}$}

\author{
${ }^{1}$ Faculty of Medicine and Biomedical Sciences of Yaoundé, Yaoundé, Cameroon \\ ${ }^{2}$ Douala General Hospital, Douala, Cameroon \\ ${ }^{3}$ Yaoundé General Hospital, Yaoundé, Cameroon \\ ${ }^{4}$ Yaoundé Teaching Hospital, Yaoundé, Cameroon \\ Email: *mendjouf@yahoo.fr
}

How to cite this paper: Danielle, F.M.E.E.H., Berinyuy, L.C., Maimouna, M., Bandolo, N.V., Emmanuel, N. and Francois, K.F. (2020) Clinical Profile and Outcome of Acute Kidney Injury in Elderly Adults in a Tertiary Hospital in Cameroon. Open Journal of Nephrology, 10, 311-322.

https://doi.org/10.4236/ojneph.2020.104031

Received: October 1, 2020

Accepted: November 1, 2020

Published: November 4, 2020

Copyright $\odot 2020$ by author(s) and Scientific Research Publishing Inc. This work is licensed under the Creative Commons Attribution International License (CC BY 4.0).

http://creativecommons.org/licenses/by/4.0/

\begin{abstract}
Background: Elderly patients have a high risk of acute Kidney Injury (AKI) due to aging, decreased renal function and the presence of comorbidities. There is limited data on AKI in elderly patients in low income regions, especially in Sub-Saharan Africa. We therefore sought to describe the clinical profile and outcome of AKI in elderly in a tertiary hospital in Cameroon. Methods and Materials: We reviewed the medical records of all patients admitted with the diagnosis of AKI in the internal medicine unit of the Yaounde University Teaching Hospital, from January 2015 to February 2018. Records of elderly patients ( $\geq 65$ years) were retrieved and analysed. AKI was diagnosed and classified using the KDIGO (Kidney Disease Improving Global Outcomes) 2012 classification. The diagnosis, aetiologies and mechanisms of AKI were clinical. Renal outcomes were evaluated on day 7, 14, 28, 60 and 90 of hospital stay. Results: We included 76 elderly $(66 \%$ males) patients with a median [interquartile rate-IQR] age of 69 [65 - 75] years. Hypertension (60.5\%), diabetes mellitus (36.8\%) and heart failure (26.3\%) were the most common comorbidities. The median [IQR] Charlson index was 4 [3 - 5]. Infections (47.4\%) and hypovolemia (69.7\%) were the most frequent risk factors for AKI. AKI was mainly community acquired (89.5\%) and most of the patients were in stage $2(34.2 \%)$ or 3 (29\%). Pre-renal AKI (58\%) was the leading mechanism involved. Hypovolemia and sepsis were the most common aetiologies. Of the $14.5 \%$ with indication for dialysis, only $2.6 \%$ had access to it. The overall prognosis was good with a mortality rate of $2.6 \%$, complete and partial renal recovery at 3 months of $70 \%$, and $26.3 \%$ respectively. Conclu-
\end{abstract}


sion: AKI in the elderly, in our setting was community-acquired and affected mainly those with comorbidities. Pre-renal AKI was the main mechanism; hypovolemia and sepsis were the major aetiologies. Most participants had complete renal recovery at 3 months.

\section{Keywords}

AKI, Elderly, Community Acquired, Hypovolemia, Sepsis

\section{Introduction}

Acute Kidney Injury (AKI) is an abrupt decline in glomerular filtration rate resulting in accumulation of nitrogenous waste products, hydro-electrolytes imbalance and acid-base disorders. AKI is common, affecting about 13.3 million people worldwide per year [1]. It is also associated with prolonged hospital stay, poor patient outcomes including death and chronic kidney disease [2]. AKI can be due to several conditions such as hypovolemia, sepsis and nephrotoxic drug use. It is encountered in multiple settings and in all age groups. The elderly are more predisposed to developing AKI, either due to kidney senility, or because of high prevalence of comorbidities, which prone them to undergo several procedures, which are also risk factors of AKI [3]. Moreover, in high income regions, high socioeconomic development, increase prosperity and improved medical facilities led to increasing life expectancy, hence an increase in the demand of the elderly population for health service. Thereby, in such countries, AKI mainly affects older patient admitted in intensive care unit with high comorbid burden and usually in a context of multiple organ failure [1]. An analysis of Medicare beneficiaries from 2005 to 2015 in the United States showed that the rate of AKI increases stepwise from 26.8 episodes (66 - 69 years) to 37.4 episodes (70 - 74 years) to 55.4 episodes (75 - 79 years) to 77.1 episodes ( 80 - 84 years) to 110.5 episodes (85 years and older) per 1000 patient-years, respectively [4]. AKI in the elderly also carries a high risk of both short-term and long-term mortality, while survivors often end up with chronic kidney disease which may progress to end-stage renal disease [3] [4] [5] [6] [7]. The risk of end-stage renal disease may be 13 times higher in hospitalized elderly patients with AKI compared to elderly patients without AKI [7]. An absolute 2-year mortality risk increase of $29 \%$ for elderly patients with AKI compared to their elderly counterparts without AKI had also been reported [7]. Furthermore, older patients with AKI experience decreased functional status and impaired quality of life, both contributing to adverse outcomes as well as long term morbi-mortality.

In developing countries, there is scarcity of data on the epidemiology of AKI although it is estimated that $85 \%$ of people with AKI live there [1]. In Sub-Saharan Africa, AKI is reported as community-acquired, affecting young healthy people and usually due to preventable conditions such as malaria or diarrheal disease [1] [8] [9]. Mortality is higher ranging from $32 \%$ to $86 \%$ de- 
pending on dialysis accessibility [9]. However, increase in life expectancy has also been noted in these areas. From 1960 to 2018, life expectancy in Sub-Saharan Africa rose from 40 years to 62 years [10]. Meanwhile, a non-neglected proportion of the elderly may experience AKI. As reported by Yao and al, in Ivory Coast [11], mortality among them may be higher compared to younger participants due to environmental setting (inaccessibility to appropriate medical care, reduced capacity to provide intensive care), lack of dialysis facility, financial constraint and comorbid factors. Our aim was to describe the epidemiology of AKI among elderly adults in a tertiary hospital in Cameroon.

\section{Methods and Materials}

\subsection{Study Setting}

We conducted a descriptive study from $1^{\text {st }}$ January 2015 to $28^{\text {th }}$ February 2018 at the Yaounde University Teaching Hospital. This health facility is in the political capital of Cameroon and is one of the 6 tertiary health facilities of the country. It is one of the teaching hospitals of the faculty of medicine of the University of Yaounde 1. It consists of many services including internal medicine, surgical, pediatric, gynecological, radiology, laboratory and intensive care units. The nephrology unit is part of the internal medicine service and it is managed by two nephrologists. The dialysis unit is part of the intensive care unit and it is operational daily. Only conventional hemodialysis is available. Polysulfone dialyzers and bicarbonate dialysates are used.

\subsection{Participants}

We reviewed the medical records of all patients admitted in the internal medicine service during the study period. All records with a diagnosis of AKI were retrieved and analyzed. Record of elderly patients ( $\geq 65$ years) were identified. We excluded records with insufficient data for the diagnosis of AKI and patients with known chronic kidney disease.

\section{Methods}

We collected socio-demographic, clinical data including comorbidities, diagnosis on admission and hemodynamic parameters from the medical records. Charlson comorbidity index was used to evaluate comorbidity burden. Laboratory parameters such as hemoglobin level, white blood cell count, serum electrolytes were also collected if available. Information about etiology, mechanism and type of AKI, access to dialysis, hospital mortality and renal outcome on day 7, 14, 28, 60 and 90 of AKI diagnosis were also recorded. AKI was diagnosed and classified according to the KDIGO 2012 classification. Diagnosis of etiologies and mechanism of AKI were clinical.

The following definitions were used:

- AKI was defined base on:

$\circ$ an increase or a decrease in serum creatinine by $\geq 3 \mathrm{mg} / \mathrm{l}$ between 48 hours. 
○ an increase or decrease of at least $50 \%$ of the baseline creatinine (creatinine at admission) during the hospitalization.

- Renal recovery was reported only for survivors at discharge and was defined as.

- Complete renal recovery in case of normalization of serum creatinine within 90 days.

- Partial recovery in case of persistence of renal failure without need of dialysis in those who were receiving dialysis or decrease of at least $25 \%$ of serum creatinine.

- Pre-renal AKI was diagnosed based on history, signs of hypovolemia with urine dipstick gravity $\geq 1020$, serum urea and creatinine ratio of more than 20 , urine indices when available and normalization of renal function with volume expansion.

- Acute tubular necrosis was diagnosed based on history, presence of risk factors, urinary dipstick gravity $<1015$, urine indices when available and recovery with a polyuric phase.

- Acute interstitial nephritis was defined based on history, presence of risk factor, sterile leucocyturia and enlarged kidney.

- Post-renal AKI was defined as AKI associated with decreased urine output, urinary tract dilation on renal ultrasonography and improved renal function after removal of urinary obstruction.

- Drug induced AKI was diagnosed based on a history of ingestion of a known nephrotoxic drug (NSAID: Non-Steroidal Anti-inflammatory drug, blockers of the RAAS: renin-angiotensin-aldosterone system, Cisplatin, aminoglycoside, iodine contrast) or herbal remedies.

- Sepsis induced AKI was used for patients with clinical diagnosis of sepsis or severe infection together with white blood cell count $\geq 12,000 / \mathrm{mm}^{3}$ and a blank urinary dipstick.

- Need of dialysis referred to patients with indications for dialysis.

- Access to dialysis referred to those who actually benefited from dialysis after the indication was made.

- Sepsis was defined as the presence of a proven or suspected microbial infection in the presence of at least two of the following criteria:

- Temperature $>38^{\circ} \mathrm{C}$ or $<36^{\circ} \mathrm{C}$.

- Pulse rate $>90$ beats/minute.

- Respiratory rate $>24$ cycles/minute.

○ White cell count $>12,000$ cells $/ \mathrm{mm}^{3}$ or $<4000$ cells $/ \mathrm{mm}^{3}$.

- Anemia was considered for Hemoglobin level $<10 \mathrm{~g} / \mathrm{dl}$.

- Very elderly patients referred to patients of 80 years of age and above.

Statistical analysis and ethical considerations:

Data was analyzed using SPSS version 22.0. Continuous data were summarized as means or median as appropriate, while qualitative data were presented as percentages. Chi-square and Student test were used to compare data among 
age groups. A statistical significance was set at a p-value $<0.05$.

The study was approved by the Ethical Committee for research of the Faculty of Medicine and Biomedical Sciences of Yaounde. All ethical principles were respected.

\section{Results}

During the study period, 85 elderly patients were identified among 194 medical records found with the diagnosis of AKI. Nine patients were excluded because of known CKD or insufficient data to discriminate AKI from CKD. Hence, a total of 76 elderly patients were included with $66 \%(n=50)$ being males. The median [IQR] age was 69 [65 - 75] years with extremes of 65 to 87 years; $50 \%(n=38)$ were between 65 to 69 years and 14.5\% $(n=11)$ were very elderly. Hypertension $(60.5 \%)$ and diabetes mellitus $(36.8 \%)$ were the main comorbidities. Heart failure was more common in very elderly ( $\geq 80$ years: $63.6 \% ; p=0.003$ ). Charlson index ranging from 0 to 8 , was comparable between age groups (65 to 69 years $=4.31 \pm 2.6 ; 70$ to 79 years $=4.22 \pm 1.8 ; \geq 80$ years $5.7 \pm 1.5 ; \mathrm{p}=0.06)$. Infectious conditions were the mains reasons for admission. Decreased urine output was reported in $15.8 \%(\mathrm{n}=12)$ of participants, Table 1 .

Twenty-five (33\%) patients had hypotension on admission (65 to 69 years = $26.3 \% \mathrm{n}=10 ; 70$ to 79 years $=33.4 \% \mathrm{n}=9$, $\geq 80$ years $54.5 \% \mathrm{n}=6 ; \mathrm{p}=0.6$ ). Out of the 11 patients with available serum bicarbonate levels, 8 had metabolic acidosis. The mean serum potassium was $4.6 \pm 1.2 \mathrm{mmol} / \mathrm{l}$, Table 2 .

AKI was mainly community-acquired $(n=66,87 \%)$ and stage 3 was found in $36.8 \%$ of patients. Most of the patients had pre-renal AKI ( $\mathrm{n}=44,58 \%)$ while $17.1 \%(\mathrm{n}=13)$ had acute tubular necrosis. Pre-renal AKI was more common among very elderly $(72.7 \%, \mathrm{n}=8)$ and intrinsic AKI was more common in the elderly $<70$ years $(50 \%, \mathrm{n}=19)$. Hypovolemia and malignant hypertension were the main causes of AKI in very elderly patients. In younger patients, AKI was mainly due to hypovolemia, sepsis and nephrotoxic drugs, Table 3.

Dialysis was indicated in $11(14.5 \%)$ patients. Dialysis indication was similar among age group ( $65-69$ years $10.5 \% n=5 ; 70-79$ years $18.6 \% n=5 ; \geq 80$ years $9.1 \% \mathrm{n}=1 ; \mathrm{p}=0.8)$. Hyperkaliemia was the main indication for dialysis. Among the 11 patients with indications, only 2 patients had access to dialysis. Age and hypotension were the main reason of non-access to dialysis, Table 4.

Two deaths $(2.6 \%)$, due to septic choc, were registered during hospital stay. One patient left against medical advice within the 7 days of hospital stay. Amongst survivors, 51 patients (70\%) had a complete renal recovery, 20 patients $(27.3 \%)$ had partial renal recovery and 2 patients $(2.7 \%)$ had no renal recovery, Figure 1. Among patients with complete follow up data available after 3 months, $8(11 \%)$ developed chronic kidney disease). Outcome was comparable among age group, Table 5 .

\section{Discussion}

AKI in low income countries usually affects young people with less comorbid 
Table 1. Socio-demographic data, comorbidity and clinical data.

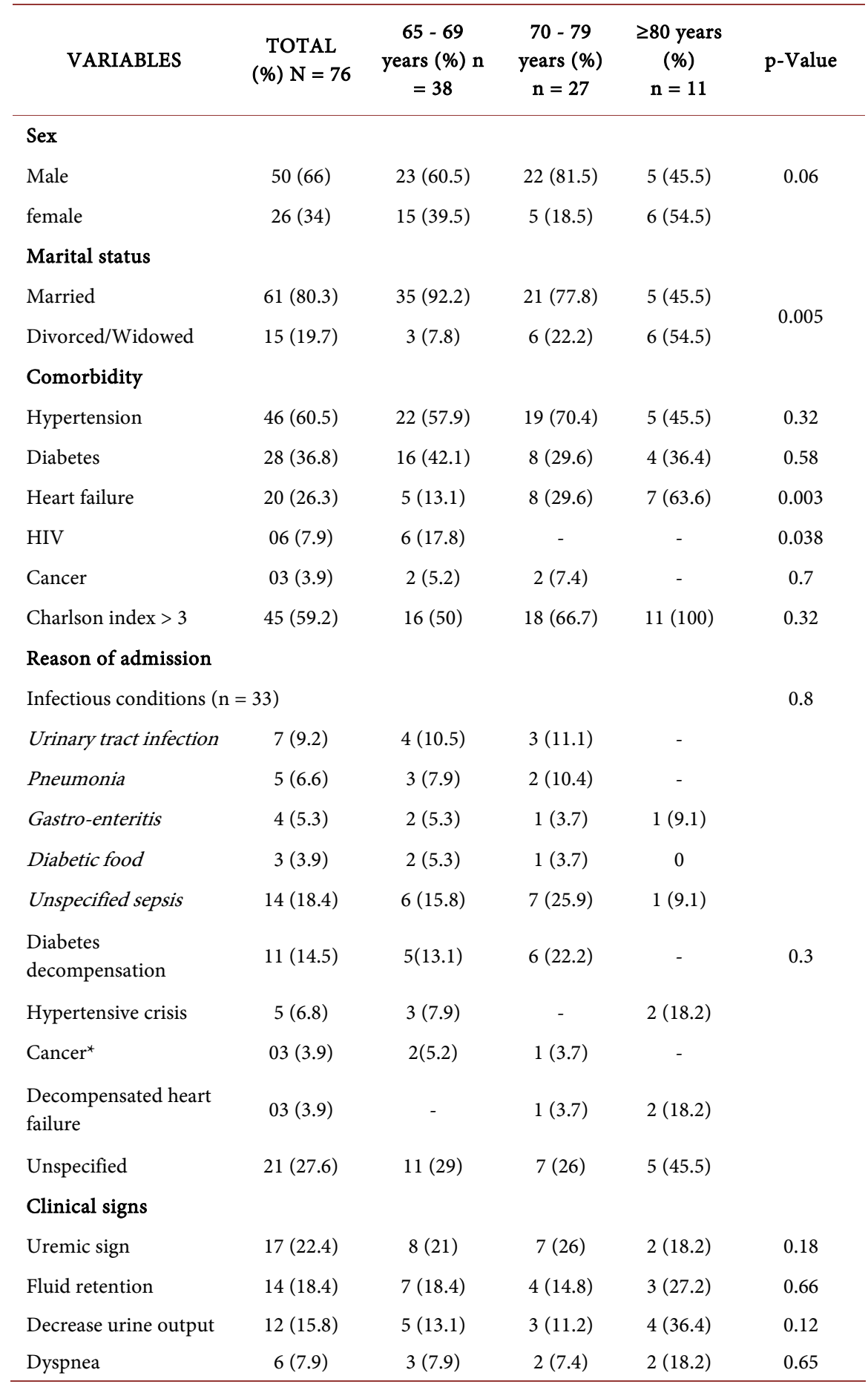

${ }^{\star}$ Cancer included prostate cancer $(n=2)$ and cervix cancer $(n=1)$.

factors while older population are typically found in developed countries [12] [13]. However, we found a significant proportion of elderly (41\%) among patient admitted with AKI in our setting. AKI in elderly has been described in other Cameroonian studies with a frequency of $20 \%-30 \%$ of patient older than 60 years [12] [13]. Yao et al., in Ivory Coast also noted a significant proportion of 
Table 2. Blood pressure and laboratory data.

\begin{tabular}{|c|c|c|c|c|c|}
\hline VARIABLES & $\begin{array}{c}\text { Total (\%) } \\
\mathrm{N}=76\end{array}$ & $\begin{array}{c}65-69 \\
\text { years (\%) } \\
n=38\end{array}$ & $\begin{array}{c}70-79 \text { years } \\
(\%) n=27\end{array}$ & $\begin{array}{c}\geq 80 \text { years } \\
(\%) \\
N=11 \\
\end{array}$ & $\begin{array}{c}\mathrm{p}- \\
\text { value }\end{array}$ \\
\hline $\begin{array}{l}\text { Systolic blood } \\
\text { pressure }(\mathrm{mmHg})\end{array}$ & $130 \pm 30$ & $134 \pm 30$ & $131 \pm 30$ & $114 \pm 27$ & 0.15 \\
\hline $\begin{array}{l}\text { Diastolic blood } \\
\text { pressure }(\mathrm{mmHg})\end{array}$ & $76 \pm 16$ & $77 \pm 15$ & $76 \pm 16$ & $69 \pm 18$ & 0.35 \\
\hline $\begin{array}{l}\text { White blood cell } \\
\left(\text { cell } / \mathrm{mm}^{3}\right)\end{array}$ & $9155 \pm 4700$ & $9460 \pm 5350$ & $9496 \pm 3890$ & $7191 \pm 4495$ & 0.38 \\
\hline $\begin{array}{l}\text { Hemoglobin } \\
\text { level }(\mathrm{g} / \mathrm{dl})\end{array}$ & $10.8 \pm 2.4$ & $10.64 \pm 2.8$ & $10.8 \pm 1.9$ & $11.13 \pm 2.57$ & 0.86 \\
\hline Sodium & $138.3 \pm 7.45$ & $137.4 \pm 6$ & $138 \pm 8.6$ & $143.7 \pm 7$ & 0.12 \\
\hline Potassium & $4.6 \pm 1.2$ & $4.4 \pm 1$ & $4.7 \pm 1.4$ & $4.8 \pm 1.3$ & 0.51 \\
\hline
\end{tabular}

Table 3. AKI characteristics according to age.

\begin{tabular}{|c|c|c|c|c|c|}
\hline VARIABLES & $\begin{array}{c}\text { TOTAL (\%) } \\
\mathrm{N}=76\end{array}$ & $\begin{array}{c}65-69 \\
\text { years }(\%) \\
n=38\end{array}$ & $\begin{array}{c}70-79 \\
\text { years }(\%) \\
n=27\end{array}$ & $\begin{array}{c}\geq 80 \text { years } \\
(\%) n= \\
11\end{array}$ & $\mathrm{p}$ \\
\hline Type of AKI & & & & & 0.9 \\
\hline Community-acquired & $66(87)$ & $33(87)$ & $23(82)$ & $10(91)$ & \\
\hline Hospital-acquired & $10(13)$ & $5(13)$ & $4(18)$ & $1(9)$ & \\
\hline Stage of AKI & & & & & 0.45 \\
\hline Stage 1 & $26(34.2)$ & $16(42.2)$ & $8(29.6)$ & $2(18.2)$ & \\
\hline Stage 2 & $22(29)$ & $8(21)$ & $10(37.1)$ & $4(36.3)$ & \\
\hline Stage 3 & $28(36.8)$ & $14(36.8)$ & $9(33.3)$ & $5(45.5)$ & \\
\hline Supposed mechanism & & & & & 0.39 \\
\hline Pre-renal AKI & $44(58)$ & $18(47.4)$ & $18(66.7)$ & $8(72.7)$ & 0.17 \\
\hline Post-renal AKI ${ }^{*}$ & $2(2.6)$ & $1(2.6)$ & $1(3.7)$ & 0 & 0.84 \\
\hline Renal AKI & $30(39.4)$ & $19(50)$ & $8(29.6)$ & $3(27.3)$ & 0.17 \\
\hline \multicolumn{6}{|l|}{ Type of renal AKI $(\mathrm{n}=30)$} \\
\hline Acute tubular necrosis & $13(17.1)$ & $8(21)$ & $4(14.8)$ & $1(9.1)$ & 0.6 \\
\hline Vascular AKI & $5(6.5)$ & $3(8)$ & - & $2(18.2)$ & 0.11 \\
\hline Unknown & $12(15.8)$ & $8(21)$ & $4(14.8)$ & - & 0.24 \\
\hline \multicolumn{6}{|l|}{ Etiologies of AKI } \\
\hline Hypovolemia* & $32(42.1)$ & $17(44.7)$ & $9(33.3)$ & $6(54.6)$ & 0.7 \\
\hline Sepsis ${ }^{\star *}$ & $22(29)$ & $11(29)$ & $10(37)$ & $1(9)$ & 0.23 \\
\hline Toxic $* * *$ & $11(14.5)$ & $5(13.1)$ & $6(21.4)$ & - & 0.2 \\
\hline Malignant Hypertension & $3(3.9)$ & $1(2.6)$ & - & $2(18.2)$ & 0.028 \\
\hline Cancer ${ }^{* * * *}$ & $2(2.6)$ & $1(2.6)$ & $1(3.7)$ & - & 0.84 \\
\hline Unknown & $6(7.9)$ & $3(7.9)$ & $1(3.7)$ & $2(18.2)$ & 0.3 \\
\hline
\end{tabular}

${ }^{\star}$ Hypovolemia included vomiting $(n=9)$, diarrhea $(n=6)$, polyuria due to diabetic decompensation $(n=$ $11)$, decompensated heart failure $(n=3)$, septic choc $(n=3) ;{ }^{* *}$ sepsis included pneumonia $(n=5)$, urinary infection $(\mathrm{n}=5)$, unspecified $(\mathrm{n}=12) ;{ }^{* *}$ Nephrotoxic drugs $=$ aminoglycoside $(\mathrm{n}=5)$, non-steroidal anti-inflammatory drugs $(n=3)$ and herbal remedies $(n=3) ;{ }^{* * * *}$ Cancer $=1$ cervical and 1 prostate cancer. 
Table 4. Dialysis indication and accessibility.

\begin{tabular}{|c|c|c|c|c|}
\hline Variable & $\begin{array}{c}\text { TOTAL (\%) } \\
\mathrm{n}=11\end{array}$ & $\begin{array}{c}65-69 \text { years } \\
(\%) n=5\end{array}$ & $\begin{array}{c}70-79 \\
\text { years }(\%) \\
n=5\end{array}$ & $\begin{array}{c}\geq 80 \text { years }(\%) \\
n=1\end{array}$ \\
\hline \multicolumn{5}{|l|}{ Indication of dialysis } \\
\hline Hyperkaliemia & $6(54.6)$ & $2(40)$ & $3(60)$ & $1(100)$ \\
\hline Metabolic acidosis & $3(27.3)$ & $1(20)$ & $2(40)$ & - \\
\hline Uremic sign & $3(27.3)$ & $1(20)$ & $2(40)$ & \\
\hline Fluid retention & $3(27.3)$ & $3(60)$ & - & - \\
\hline \multicolumn{5}{|l|}{ Effective dialysis } \\
\hline Yes & $2(18.2)$ & $1(20)$ & $1(20)$ & 0 \\
\hline \multicolumn{5}{|l|}{ Reason of non-dialysis } \\
\hline Age-related & $5(45.4)$ & $1(20)$ & $3(60)$ & $1(100)$ \\
\hline Severe hypotension & $1(9.1)$ & $1(20)$ & & - \\
\hline Not specified & $1(9.1)$ & $1(20)$ & & \\
\hline Death & $2(18.2)$ & $1(20)$ & $1(20)$ & - \\
\hline
\end{tabular}

Table 5. Outcome according to age group.

\begin{tabular}{lcccc}
\hline & $\begin{array}{c}65-69 \text { years }(\%) \\
\mathrm{n}=38\end{array}$ & $\begin{array}{c}79-79 \text { years }(\%) \\
\mathrm{n}=27\end{array}$ & $\begin{array}{c}\geq 80 \text { years }(\%) \\
\mathrm{n}=11\end{array}$ & $\mathrm{p}$ \\
\hline $\begin{array}{l}\text { Complete renal } \\
\text { recovery }\end{array}$ & $27(71)$ & $16(59.2)$ & $8(72.7)$ & \\
$\begin{array}{l}\text { Partial renal } \\
\text { recovery }\end{array}$ & $9(23.8)$ & $9(33.4)$ & $3(27.3)$ & 0.9 \\
$\begin{array}{l}\text { No recovery } \\
\text { Death }\end{array}$ & $1(2.6)$ & $1(3.7)$ & - & \\
\hline
\end{tabular}

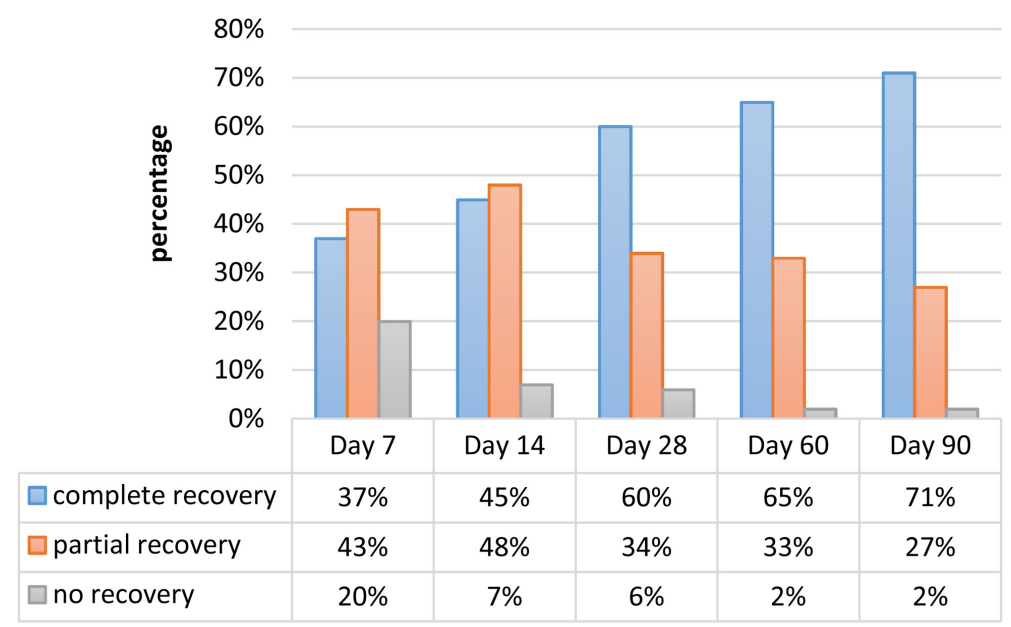

Figure 1. Overall renal outcome among survivors $(n=73)$.

the elderly with AKI [11]. This data reflects the increase in life expectancy and the susceptibility of aging kidney to AKI.

As described in the literature [12] [13] [14] comorbid burden was high in our 
population, especially among very elderly patients. As noted in our study, hypertension, diabetes and cardiac disease were the main comorbidities reported [11] [14] [15] [16] [17] [18] and are all associated with renal vasculature damage and compromised renal perfusion. The need of angiotensin blockers, which interfere with glomerular filtration, is also frequent in these pathologies. All these may contribute to increase risk of AKI in the elderly population.

Community-acquired AKI was the most frequent type of AKI. Mahesh et al., in India and Selmy et al., in Tunisia [17] [18] also found a high rate of community-acquired AKI (94\%) in the elderly with AKI. This is contrary to the findings in high income countries, where, AKI in the elderly is mainly hospital-acquired and occurred during intensive care unit stay or after major surgery [12].

AKI in our setting was severe, with most of the patients in stage 2 or 3. Similar findings had been noted by previous reports in nephrology units of low income countries [11] [15] [16] [17] [18]. Since AKI stage 1 is usually asymptomatic, those patients are generally managed by non-nephrologists and only severe cases are referred. Monitoring of urine output and routine measurements of serum creatinine could help for early detection of AKI and hence early management.

Hypovolemia and sepsis were the main aetiologies of AKI in our population. Pre-renal AKI was common and ATN was noted in $17.1 \%$ of patients. Hypovolemia and sepsis are the most common aetiologies reported in the elderly with AKI in high income as well as low income regions [11] [15]-[20] as senile kidney may be more susceptible to hypoperfusion. Experimental studies showed that older rats experience more severe kidney damage during ischemia and reperfusion manoeuvres as a result of reduced antioxidant levels and higher oxidative stress than in the kidneys of their younger counterparts [21]. Other physiologic changes noted in the aging kidney are the loss of urinary concentrating and diluting ability, diminished sodium conservation, decreased plasma renin and aldosterone levels, decreased prostaglandin production, and an enhanced response to vasoconstrictive stimuli [22]. These changes result in reduced capacity to retain salt and water thereby increasing the propensity of the elderly to develop volume depletion and dehydration.

Nephrotoxic AKI was observed in $14.5 \%$ of the elderly and was mainly due to use of aminoglycoside and herbal remedies. Nephrotoxicity is linked to $10 \%$ $20 \%$ of AKI in Cameroonian studies [14] [15] [23]. However, Yao et al., found a lower frequency of nephrotoxic AKI in the elderly (2.8\% vs $17 \%)$ compared to young adults [11]. Nephrotoxic AKI had a prevalence ranging from $3 \%$ to $7 \%$ among the elderly, as reported by other authors [17] [20].

Dialysis indication was low in our population $(14.5 \%, \mathrm{n}=11)$ as pre-renal AKI was the main mechanism of AKI. However, only 2 (18.2\%) patients had access to dialysis. Advanced age was the main reason for not doing dialysis. The initiation of renal replacement therapy in AKI is challenging and faces many controversies including time of initiation, methods use, or dose prescribed. In the elderly, the decision is more complex, since life expectancy and quality of life 
should be integrated into the treatment plan. Among patients who did not access dialysis, 2 patients died; both had sepsis and multiple comorbidities. After the 3 months follow up, 3 patients had complete remission while 4 had partial remission.

AKI in the elderly is generally reported as having a poor prognosis with increased risk of chronic kidney impairment and long-term mortality [7]. Although complete renal recovery was common in our setting; $30 \%$ of patients had partial or no renal recovery after 3 months. Eleven percent of our population developed chronic kidney disease. Yao et al., reported that $62.8 \%$ of the elderly with AKI did not normalize their kidney function after 3 months. One meta-analysis on renal recovery after AKI in the elderly revealed that $31 \%$ of the elderly failed to recover their renal function after an episode of AKI [24].

\section{Limitation}

As we conducted a retrospective study, our main limitation was selection bias. It would have been better to make a multicentre study to have the real epidemiology of AKI in the elderly in Cameroon.

\section{Conclusion}

The elderly with AKI are frequent in our setting. As reported in young adults, AKI is mainly community-acquired and diagnosed at advanced stages. Hypovolemia and sepsis are the leading aetiologies and pre-renal AKI is the main mechanism involved. Decision for dialysis is influenced by age especially among patients of 70 years and above. Some degree of renal impairment was recorded in $30 \%$ of the elderly after 3 months of AKI.

\section{Conflicts of Interest}

The authors declare no conflicts of interest regarding the publication of this paper.

\section{References}

[1] Lewington, A., Cerdá, J. and Mehta, R. (2010) Raising Awareness of Acute Kidney Injury: A Global Perspective of a Silent Killer. Kidney International, 84, 457-467. https://doi.org/10.1038/ki.2013.153

[2] Mehta, R., Cerdá, J., Burdmann, E., MarcelloTonelli, Garcia, G., Jha, V., Susantitaphong, P., Rocco, M., Vanholder, R., Sever, M.S., Cruz, D., Jaber, B., Lameire, N.H., Lombardi, R., Lewington, A., Feehally, J., Finkelstein, F., Levin, N., Pannu, N., Thomas, B., Aronoff-Spencer, E. and Remuzzi, G. (2015) International Society of Nephrology's 0by25 Initiative for Acute Kidney Injury (Zero Preventable Deaths by 2025): A Human Rights Case for Nephrology. The Lancet, 385, 2616-2643. https://doi.org/10.1016/S0140-6736(15)60126-X

[3] Yokota, G., Sampaio, B., Rocha, E., Balbi, A., Sousa Prado, I.R. and Ponce, D. (2018) Acute Kidney Injury in Elderly Patients: Narrative Review on Incidence, Risk Factors, and Mortality. International Journal of Nephrology and Renovascular Disease, 11, 217-224. https://doi.org/10.2147/IJNRD.S170203 
[4] USRDS (2017) Acute Kidney Injury. In USRDS Annual Data Report Volume 1 CKD in United Stated. Edited by National Institutes of Health, National Institute of Diabetes and Digestive and Kidney Diseases, Bethesda, 95-116. https://www.usrds.org/2017/download/v1_c05_AKI_17.pdf

[5] Xue, J.L., Franck, D., Star, R., Kimmel, P., Eggers, P.W., Molitoris, B.A., Himmelfarb, J. and Collins, A.J. (2006) Incidence and Mortality of Acute Renal Failure in Medicare Beneficiaries, 1992 to 2001. Journal of the American Society of Nephrology, 17, 1135-1142. https://doi.org/10.1681/ASN.2005060668

[6] Acunak, C.E., Grover, A., Camelo, A. and Junior, R.S. (2007) Clinical-Epidemiological Characteristics of Adults and Aged Interned in an Intensive Care Unity of the Amazon (Rio Branco, Acre). Revista Brasileira de Terapia Intensiva, 19, 304-309. https://doi.org/10.1590/S0103-507X2007000300006

[7] Ishani, A., Xue, J.L., Himmelfarb, J., Eggers, P.W., Kimmel, P.L., Molitoris, B.A. and Collins, A.J. (2009) Acute Kidney Injury Increases Risk of ESRD among Elderly. Journal of the American Society of Nephrology, 20, 223-228. https://doi.org/10.1681/ASN.2007080837

[8] Mehta, R., Burdmann, E.A., Cerdá, J., Feehally, J., Finkelstein, F., García-García, G., Godin, M., Jha, V., Lameire, N.H., Levin, N.W., Lewington, A., Lombardi, R., Macedo, E., Rocco, M., Aronoff-Spencer, E., Tonelli, M., Zhang, J. and Remuzzi, G. (2016) Recognition and Management of Acute Kidney Injury in the International Society of Nephrology 0by25 Global Snapshot: A Multinational Cross-Sectional Study. The Lancet, 387, 2017-2025. https://doi.org/10.1016/S0140-6736(16)30240-9

[9] Olowu, W., Niang, A., Osafo, C., Ashuntantang, G., Arogundade, F.A., Porter, J., Naicker, S. and Luyckx, V.A. (2016) Outcomes of Acute Kidney Injury in Children and Adults in Sub-Saharan Africa: A Systematic Review. The Lancet Global Health, 4, e242-e250. https://doi.org/10.1016/S2214-109X(15)00322-8

[10] World Bank Group. https://data.worldbank.org/indicator/SP.DYN.LE00.IN?locations=ZG

[11] KouaméYao, H., Cyr Guei, M., Weu, M.T., Konan, S.D., Séry, P.D. and Sanogoand, S. (2017) Comparative Study of Community Acute Kidney Injury in Young Patients versus Elderly Patients in an Internal Medicine Department in Abidjan (Côte d'Ivoire). Journal of Renal Injury Prevention, 6, 199-204. https://doi.org/10.15171/jrip.2017.38

[12] Cerdá, J., Bagga, A., Vijay, K. and Rajasekara, C. (2008) The Contrasting Characteristics of Acute Kidney Injury in Developed and Developing Countries. Nature Clinical Practice Nephrology, 4, 138-153. https://doi.org/10.1038/ncpneph0722

[13] Oleska, R. and Bagshaw, S.M. (2014) Acute Kidney Injury-Epidemiology, Outcomes and Economics. Nature Reviews Nephrology, 10, 193-207. https://doi.org/10.1038/nrneph.2013.282

[14] Fabio, F., Savriè, C., Alfredo De Giorgi, A., Cappadona, R., Di Simone, E., Boari, B., Storari, A., Gallerani, M. and Manfredini, R. (2019) Acute Kidney Injury and In-Hospital Mortality: A Retrospective Analysis of a Nationwide Administrative Database of Elderly Subjects in Italy. Journal of Clinical Medicine, 8, 1371. https://doi.org/10.3390/jcm8091371

[15] Fouda, H., Ashuntantang, G., Halle, M.P. and Kaze, F. (2016) The Epidemiology of Acute Kidney Injury in a Tertiary Hospital in Cameroon: A 13 Months Review. Journal of Nephrology \& Therapeutics, 6, 250. https://doi.org/10.4172/2161-0959.1000250

[16] Fouda, H., Tewafeu, D., Kombe, F., Halle, M.P., Siysi, V.V., Abderraman, M.G., 
Kaze, F.F. and Ashuntantang, G. (2018) The Clinical Pattern and Outcomes of Acute Kidney Injury in a Semi-Urban Hospital Setting in Cameroon. Journal of Nephrology \& Therapeutics, 8, 308.

[17] Eshwarappa, M., Praveen, N., Mahesh, Parampalli, R. and Konanna, G. (2017) Clinical Profile of Geriatric Acute Kidney Injury in a Tertiary Care Center from South India. Saudi Journal of Kidney Disease and Transplantation, 28, 886-890.

[18] Yosra, S., Ben Ariba, Y. and Labidi, J. (2019) Epidemiology, Diagnosis, and Etiology of Acute Kidney Injury in the Elderly: A Retrospective Analysis. Saudi Journal of Kidney Disease and Transplantation, 30, 678-685. https://doi.org/10.4103/1319-2442.261344

[19] Gong, Y., Zhang, F., Ding, F. and Yong, G. (2012) Elderly Patients with Acute Kidney Injury (AKI): Clinical Features and Risk Factors for Mortality. Archives of Gerontology and Geriatrics, 54, e47-e51. https://doi.org/10.1016/j.archger.2011.05.011

[20] Funk, I., Seibert, E., Markau, S. and Girndt, M. (2016) Clinical Course of Acute Kidney Injury in Elderly Individuals above 80 Years. Kidney and Blood Pressure Research, 41, 947-955. https://doi.org/10.1159/000452599

[21] Kusaka, J., Koga, H., Hagiwara, S., Hasegawa, A., Kudo, K. and Noguchi, T. (2012) Age-Dependent Responses to Renal Ischemia-Reperfusion Injury. Journal of Surgical Research, 172, 153-158. https://doi.org/10.1016/j.jss.2010.08.034

[22] Abdel-Kader, K. and Palevsky, M.P. (2009) Acute Kidney Injury in the Elderly. Clinics in Geriatric Medicine, 25, 331-358.

https://doi.org/10.1016/j.cger.2009.04.001

[23] Halle, M.P., Chipekam, N.M., Beyiha, G., Fouda, H., Coulibaly, A., Hentchoya, R., Kaze, F.F., Luma, N.H. and Ashuntantang, G. (2018) Incidence, Characteristics and Prognosis of Acute Kidney Injury in Cameroon: A Prospective Study at the Douala General Hospital. Renal Failure, 40, 30-37. https://doi.org/10.1080/0886022X.2017.1419970

[24] Schmitt, R., Coca, S., Mehmet, K., Tinetti, M., Cantley, L.G. and Parikh, C.R. (2008) Recovery of Kidney Function after Acute Kidney Injury in the Elderly: A Systematic Review and Meta-Analysis. American Journal of Kidney Diseases, 52, 262-271. https://doi.org/10.1053/j.ajkd.2008.03.005 